syrup urine disease (MSUD). Helv. Paediat. Acta, 27: 449 (1972).

29. Schulman, J. D., Lustberg, T. J., Kennedy, J. L. Museles, M., and Seegmiller, J. E.: A new variant of maple syrup urine disease (branched chain ketoaciduria). Amer. J. Med., 49: 118 (1970).

30. Scriver, C. R., Mackenzie, S., Clow, C. L., and Delvin, E.: Thiamine-responsive maple syrup urine disease. Lancet, $i: 310$ (1972).

31. Scriver, C. R., and Rosenberg, L. E.: Branched chain amino acids. In: Amino Acid Metabolism and Its Disorders, p. 256 (Saunders, Philadelphia, 1973)

32. Seufert, D., Herlemann, E.-M., Albrecht, E., and Seubert, W.: Purification and properties of pyruvate carboxylase from rat liver. Hoppe-Seyler's Z. Physiol. Chem., 352: 459 (1971)

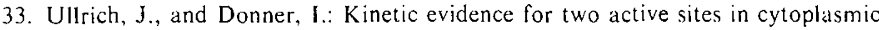
yeast pyruvate decarboxylase. Hoppe-Seyler's Z. Physiol. Chem., 35l: 1026 (1970)

34. Wendel, U.: Unpublished data.

35. Wendel, U., Rüdiger, H. W., Passarge, E., and Mikkelsen, M.: Maple syrup urine disease: Rapid prenatal diagnosis by enzyme assay. Humangenetik, 19. 127 (1973)

36. Wendel, U., Wentrup, H., and Ruidiger, H. W.: Unpublished data.

37. Wendel, U., Wöhler, W., Goedde, H. W., Langenbeck, U., Passarge, E., and Rüdiger, H. W.: Rapid diagnosis of maple syrup urine disease (branched chain ketoaciduria) by micro-enzyme assay in leukocytes and fibroblasts. Clin.
Chim Actid 45: 433 (1973).

38. Differences in the data for $H G$ and $S S$ from those in previous publications ( 16 $37)$ are due to a modified assay procedure. In contrast to the previous study the fetal calf serum was freed from amino acids by gel filtration.

39. Radiochemical Centre, Amersham, England.

40. Calatomic, Los Angeles, Calif.

41. Gibco, New York, N.Y.

42. Serva, Heidelberg, Germany,

43. The program for the mathematical analysis was written by Dr. Plesser Max-Planck-Institut für Ernährungs-physiologie, Dortmund, West Germany.

44. This paper is part of the M.D. thesis of $H$. Wentrup.

45. This research was supported in part by the Deutsche Forschungsgemeinschaft.

46. For the supply of skin or fibroblasts of the patients with MSUD we are indebted to Dr. C. Colombel, Lyon $(C C)$, Dr. L. Elsas, Atlanta $(K C)$, Dr. V. A. McKusick, Baltimore $(A R)$. Dr. H. J. Bremer, Düsseldorf $(S L)$, Dr. P. Koepp, Hamburg $(H G)$. Dr. W. Hagge and Dr. W. Roland, Stuttgart $(S S)$. Dr. L. Schuchmann, Freiburg $(K Q)$, and Dr. U. Wiesmann, Bern $(A G)$. The authors thank Dr. U. Langenbeck for critical discussion and Dr. E. Passarge for support in preparing the manuscript.

47. Requests for reprints should be addressed to: U. Wendel, M.D., University Children`s Hospital, D-4000 Düsseldorf, Moorenstr. 5, (West Germany)

48. Accepted for publication April 28, 1975.

\title{
Pyritinol Hydrochloride and Cognitive Functions: Influence on Children in Slow Learner Classes
}

\author{
Departments of Pediatrics, Neurology, and Clinical Pharmacology, University of Berne, Berne, Switzerland \\ U. WÄLTI, (37) M. KUENZLER, J. SCHILD, F. VASSELLA, E. PAVLINCOVA, J. BIRCHER, \\ AND N. HERSCHKOWITZ
}

\section{Extract}

Pyritinol-HCl was tested for its impact on the cognitive functions of children with learning disabilities. This study is a contribution to scientific discussion on the complicated methodologic problems in evaluating the clinical efficacy of psychopharmacologic agents.

Sixty-seven pupils of slow learner classes between the ages of 11 and 16 years were treated for 6 months with $300 \mathrm{mg}$ pyritinol$\mathrm{HCl} / \mathbf{2 4} \mathrm{hr}$ or placebo under strict double-blind conditions. Drug intake was stimulated and controlled by means of intense psychosocial interaction with the mothers of the subjects.

The dependence variables used to test medication effects were 22 parameters of cognitive performance measured in psychologic tests for perceptual and intellectual functions which were administered immediately before and after the medication phase.

First the gainscores before and after treatment with pyritinol or placebo within the 22 cognitive parameters were statistically compared. In addition, an analysis of covariance on the corrected results of the second test (treating the results of first testing as covariates) and a two group discriminant analysis for overall differences were performed.

None of the 22 parameters showed statistically significant treatment effects with respect to average performance ( $t$ (pyritinol - placebo $)=1.96$ to 1.31 ), neither could the two groups be separated by discriminant analysis (Hotelling's $T^{2}=\mathbf{3 5 . 4}, \mathrm{df}-$ 22 and $43, P=0.465$ ).

With respect to variability of gainscores, however, in four parameters there was a significantly higher variance in the pyritinol group $(F=1.85-2.33, P<0.05,<0.02$, respectively $)$. This fact may signify that pyritinol-HCl had different effects on different subjects. By means of prognostic stratification we therefore at- tempted to define objective criteria for a selection of subjects with probable positive treatment effects. None of the 15 tested criteria, such as body weight, age, perceptual handicaps, or reduced short term memory, IQ range, proved, however, to be critical for a prognosis of pyritinol effects within the present test population.

\section{Speculation}

Although there is no evidence for a general improvement of cognitive functions within the whole test population through treatment with pyritinol- $\mathrm{HCl}$, the results presented suggest slight medication effects in a positive as well as a negative direction for not as yet specifiable subpopulations. The definition of objective indications for the drug seems to be a major problem in testing psychopharmacologic agents.

In consideration of the increasing number of psychoactive drugs and the increasing tendency to administer them to children with behavioral and/or cognitive disorders, one could expect an increasing number of publications concerning behavioral and cognitive changes in children under the influence of psychopharmacologic agents. Nevertheless, an old complaint (6) on the lack of actual research in this field still holds true. In the last decade publications on this subject were extremely rare and some of the existing studies do not fulfill elementary methodologic criteria, as formulated by Taber (30), for clinical drug trials. At a first glance, these facts are surprising, especially with respect to the topic of drug influences on cognitive functions. Psychology has developed a great variety of cognitive tests which provide objective criteria for measuring drug influences. Several authors $(7,16,25,26)$, however, stress the considerable difficulties, such as patient-drug interactions, inter- 
vening personality variables, and complexity of multivariate experimental designs, which have to be taken into account in this area of research. This is no reason, however, to end the whole discussion since drug testing includes not only testing for safety with regard to harmful side effects but also the decisive assessment of the drug's effectiveness. The effectiveness of psychoactive drugs can in most cases be tested only through attempts to quantify behavioral characteristics. This study is intended to be a contribution to the discussion of this topic.

Pyritinol- $\mathrm{HCl}$ (34), whose chemical, pharmacokinetic, and metabolic characteristics have been described elsewhere $(5,11,15$, $21-23$ ), is used frequently as a "psychoenergizer" by psychiatrists and pediatricians. The producer's recommendations for pediatric applications of the drug include indications such as speech disorders, underachievement, social and emotional disorders, and developmental retardation. Clinical evidence seems to confirm therapeutic effects within the above areas $(10,12,14,20,24)$, whereas a double-blind study with a small sample $(n=19)$ of children with specific brain dysfunctions but with average "overall intelligence" (13) showed a tendency to increased activity combined with reduced "control functions" under the drug. On the other hand, in a second double-blind study (27) on a sample of 21 pupils with attentional dysfunctions, the pyritinol group showed a significantly greater gainscore in some cognitive parameters in comparison with the placebo group.

Since pyritinol- $\mathrm{HCl}$ is advertised and obviously in use for the treatment of "developmental retardation" it is surprising that only two of the above mentioned studies $(12,24)$ deal explicitly with mentally retarded children. Moreover, both of them are based on clinical observations without a control group and cannot, therefore, be taken into further consideration.

Aware of the experiences with glutaminic acid and similar substances, none would expect that a drug could simply "correct" the learning difficulties of slow learners. However, it remained necessary to test the probable effects of pyritinol- $\mathrm{HCl}$ on the cognitive functions of the members of such a population.

\section{SUBJECTS}

The test population consisted of 67 pupils from slow learner classes, divided into a pyritinol group $(n=35)$ and a placebo group $(n=32)$.

Slow learner classes within the Bernese school system are constituted of children who have proven to be unable to follow the learning task of the elementary school, but whose learning abilities are superior to those of the members of retarded classes. At the time when these children are tested with respect to their pass over to the slow learner class, their IQs range, as a rdle, between 75 and 90 . Since the children of this population have attended slow learner classes for several years, the actually observed IQ variation, as shown in Table 1, is even greater and reaches the upper end of the normal range. The test population also is not homogeneous with respect to specific learning disabilities, such as organic brain disfunction or dyslexia; however, there is no systematic difference between the pyritinol and placebo group.

The children were allocated to each group by the clinic's pharmacy without communication to the experimenters about group membership of the subjects. This allocation was performed with respect to body weight in order to avoid asymmetry of the two groups on this variable. In consideration of the results of an earlier study (13), hyperactive children were excluded. Also excluded were subjects under continuous medication (antiepileptica, etc.) and subjects suspected of unreliability in taking the tablets. Informed consent of the parents was a strict condition for the participation of a child in the study. Table 1 summarizes the main statistic data for the test population. Although there is no relevant difference between the pyritinol and the placebo group with respect to age, body weight, and IQ, these parameters show considerable variation within the groups. As will be shown, this heterogeneity allows the testing of several hypotheses about pyritinol activity within some subgroups.

\section{METHODS}

Each individual underwent two examinations with an interval of 6 months. In the meantime the children took the agent in a dosage of $300 \mathrm{mg} / 24 \mathrm{hr}$, or placebo. There was no possibility during the tests for subjects or examiners to find out whether pyritinol or placebo was given to a certain child, nor did the subjects know that not all of the participants received the same tablets.

An often ignored problem, not only in experimental designs, but also in medical outpatient treatment is the unreliability of patients or test subjects in taking the prescribed drug (19) and the difficulty in establishing suitable control methods. Even sophisticated objective methods, such as adding a chemical marker to the test drug, which can be pointed out by a simple urine test, have led to arbitrary results (4). This kind of method as well as a biochemical proof of pyritinol- $\mathrm{HCl}$ or its metabolites in the urine were not feasible for the present study for several technical reasons. We, therefore, attempted to control and to optimize the reliability of drug intake through psychosocial interaction. The psychologist who performed the cognitive testing took care in establishing a solid social contact with the mothers of the subjects. This contact was maintained by periodic phone calls and in some cases by personal discussions. In several cases the psychologist was consulted by the parents about educational and school problems. Moreover, the teachers of the subjects were informed about the aim of the study in the course of special meetings. A second possibility for reliability control was provided by the condition that after the first test session the mothers of the subjects received tablets only for half of the test period. They were instructed to come for the second portion after 3 months. Only two cases did not fulfill this condition and were therefore excluded.

Table 2 gives a survey of the 22 dependent cognitive parameters measured before and after medication. This test battery was compiled with the intention of getting a pattern of the cognitive functions of an individual as complete and as differentiated as possible with respect to test time. The classification criteria A to $G$ are to some extent oriented on the psychodiagnostic model of Mark (18). This design should allow for functional interpretations of possible medication effects, since it is not likely that such effects would include the whole area of cognition resulting, e.g., in a general IQ rise. The duration of a test session was about 3-4 hr plus adequate recreation phases.

With each test session a CBG and an EEG were performed. Before the first session each subject underwent a physical examination.

\section{RESULTS}

Statistical evaluation was required to eliminate common sources of variation, such as placebo effects and learning effects due to test repetition, in order to isolate the critical variance due to treatment effects. The first computation therefore dealt with a comparison of the average gainscores (difference of test 2 - test 1 ) between the two groups by Student's $t$-test for independent samples.

As demonstrated by Figure 1 the differences between the two groups with respect to average gainscores show a random distribution around the zero point. There is no statistically significant difference between the pyritinol and placebo groups with respect to changes in average performance in the 22 dependent cognitive variables.

Recently this kind of approach (computing gainscores) was subject to methodologic discussion (28). Therefore a second, statistically somewhat more complicated, approach was attempted. Based on the results of the tests after treatment, a two-factorial analysis of covariance was computed, using the results of the first testing as covariates. Factor A dealt with IQ 
Table 1. Comparison of two groups with respect to distribution of age, body weight, and IQ

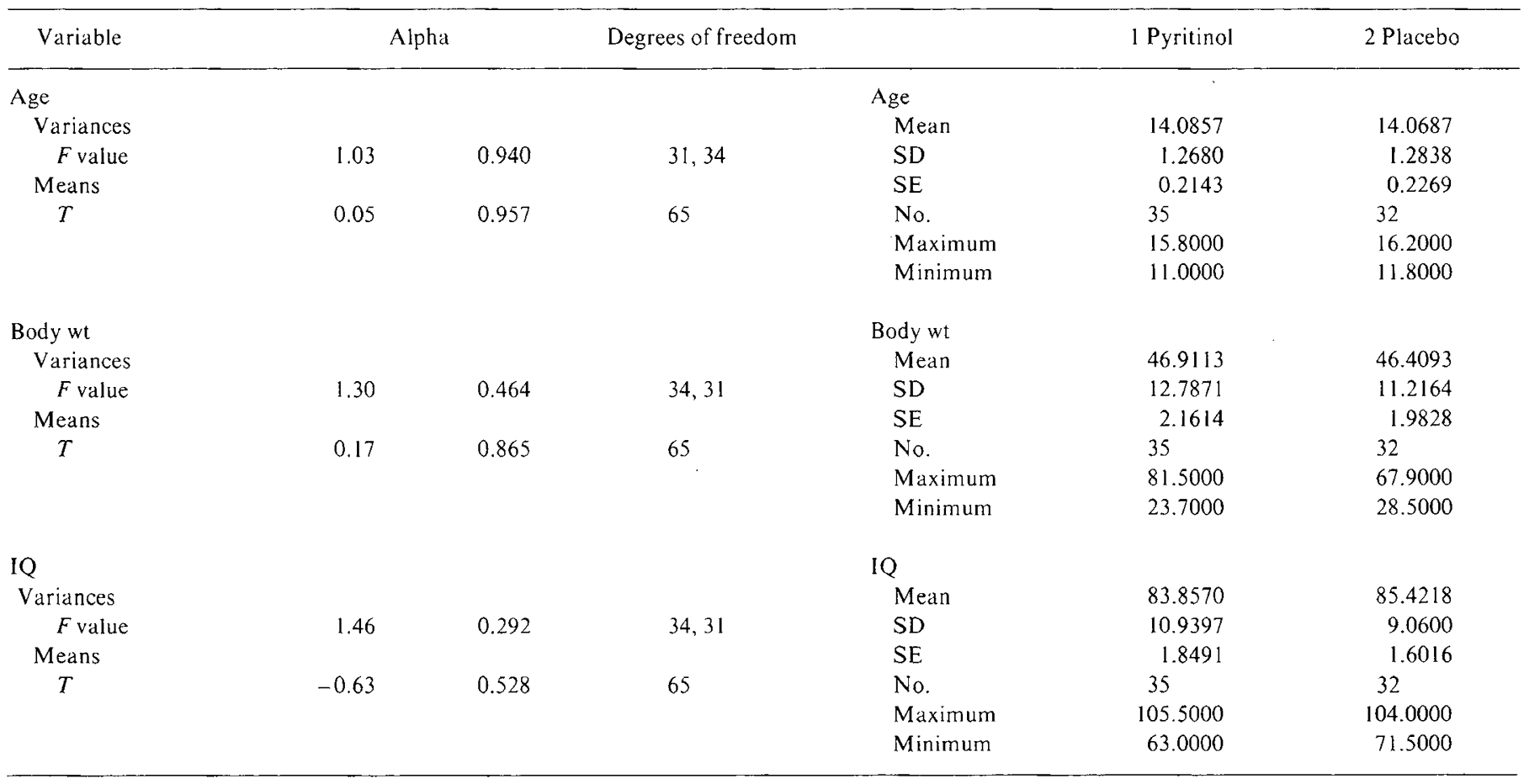

Table 2. Dependent variables: Cognitive parameters measured before and after medication ${ }^{1}$

\begin{tabular}{cl}
\hline A. Speed of visual & 1. Critical flicker frequency (32) \\
perception & 2. Tachistoscope syllables (17) \\
& 3. Tachistoscope figures (17) \\
& 4. Tachistoscope words (17) \\
& 5. Color blots (29) \\
6. Color-word interference (29) & 7. Block design (8) \\
B. Nonverbal; short range & 8. Form board (1) \\
attention & 9. Object assembly (8) \\
C. Nonverbal; continuous & 10. Knox cubes (1) \\
attention & 11. Paper fold (9) \\
& 12. Benton test (2) \\
D. Verbal; short range & 13. Test d2 (3) \\
attention & 14. Repeating digits and sentences (31) \\
E. Verbal; continuous & 16. Repeating digits reversed (8) \\
attention & 17. Retelling short story \\
& 18. Learning KVK-structures \\
19. Similarities (8) & 20. Oral arithmetic (8) \\
F. Academic skills & 21. Dictation \\
G. General level & 22. IQ (combined score)
\end{tabular}

${ }^{1}$ Numbers in parentheses refer to the list of references.

ranges (IQ below or above 85), factor B with treatment (pyritinol or placebo). However, in accordance with the above mentioned results, neither significant treatment effects nor significant medication/IQ-interactions could be found and a detailed description of the results can be omitted. As a last test with respect to possible changes of average performance after medication, Hotelling's $T^{2}$ was computed. A $T^{2}$ of 35.4 with degrees of freedom of 22 and 43 has a probability of 0.465 . In other words the pyritinol and the placebo groups cannot be differentiated statistically with respect to average gainscores in all parameters.

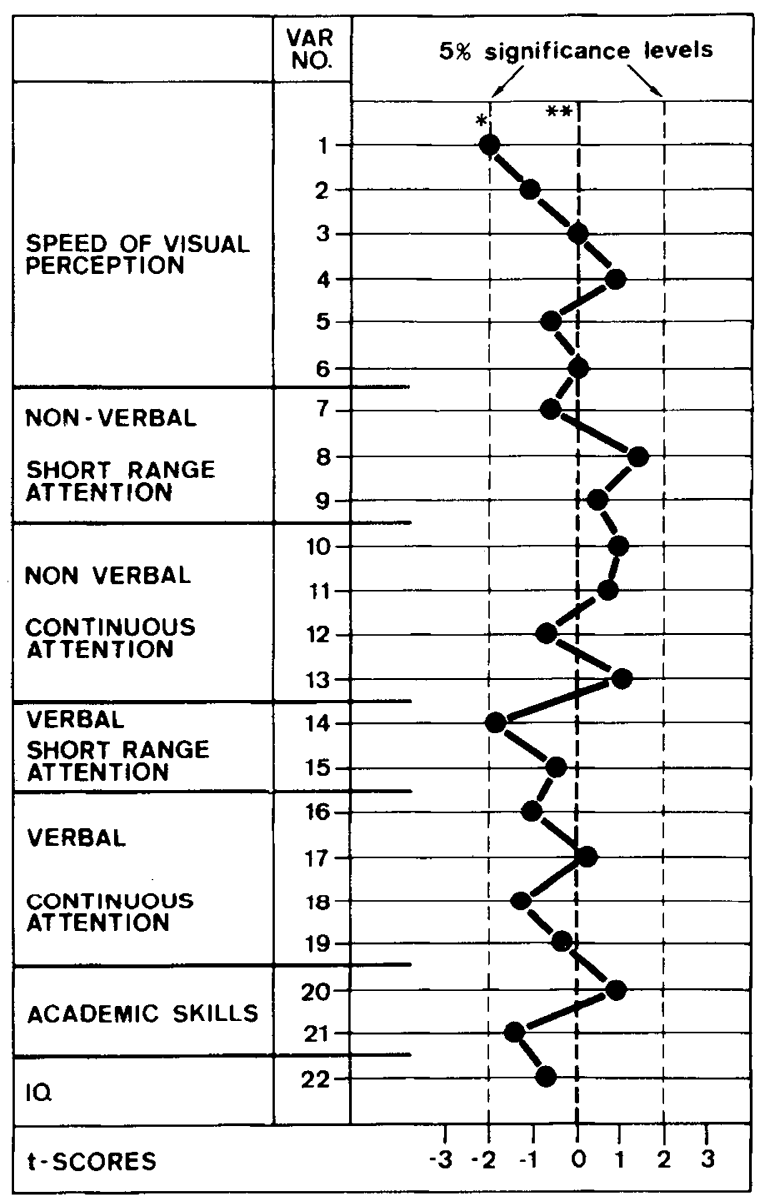

Fig. 1. Comparison of gainscores after treatment by Student's $t$-test (pyritinol group-placebo group). By $t$-transformation the averages of the placebo group are set as $0 . *$ : transformed mean gainscores for pyritinol group; **: transformed mean gainscores for placebo group. 
However, a second kind of hypothesis had to be tested. There is a theoretical possibility that pyritinol- $\mathrm{HCl}$ has different effects on different subjects. If there were subjects with improvement and subjects with deterioration of cognitive performance under treatment, those effects could be hidden with respect to average performance, whereas a comparison of the variances of gainscores between the two groups would show significantly increased variance within the pyritinol group.

In 4 of the 22 parameters, as shown in Table 3, the pyritinol group indeed shows significantly higher variances of the gainscores than the placebo group. It was therefore hypothesized that there probably exists a subgroup with positive treatment effects, and several attempts were undertaken to define objective criteria for the selection of the probable members of such a subgroup (prognostic stratification). Subgroups were selected using the following criteria: body weight (below/above average), age (below/above average), IQ range (several subgroups), reaction speed (below/above average on several tests using a time parameter), short range memory (below/above average on the test "digits and sentences"). Although 15 pairs of pyritinol/placebo subgroups were selected using the above mentioned criteria and analyzed for treatment effects, none showed significant changes on any of the 22 cognitive parameters after medication for the pyritinol group in comparison with the analogous placebo group. The tendency to increased variability of gainscores for the pyritinol group, however, remained constant within the selected subgroups. With respect to EEG and blood smear, no relevant changes were observed during the test period.

\section{DISCUSSION}

The earlier studies dealing with the present topics $(10,12-14,20$, $24,27)$ are considerably different with respect to methodology and/or test population. A comparison of the presented results with earlier findings would therefore lead to arbitrary speculation. Hence the following interpretation refers only to proper findings.

As a general result it must be stated that pyritinol- $\mathrm{HCl}$ does not improve cognitive functioning in slow learner class pupils as a group. An exclusion of methodologic errors as an explanation for this fact seems to be justified, since the applied test battery has proven to be valid for clinical purposes as well as for experimental designs (33) and the computer data analysis corresponds to present practice of applied statistics. With respect to the test agent, therefore, the first conclusion is that the intention to improve cognitive functioning in children with learning disabilities is no general indication for the prescription of pyritinol- $\mathrm{HCl}$.

The fact, however, that the pyritinol group as opposed to the placebo group showed significantly higher variance of gainscores after treatment, although only in 4 of 22 variables, leads to the second conclusion that there is probably a subgroup of subjects which show a certain positive pyritinol effect on some cognitive parameters (as well as a subgroup with negative effects). These subjects could be designated as "potential pyritinol patients" and therefore it would be essential for an efficient clinical application of the drug to get objective criteria for a selection of these patients. The indication list provided by the producer gives no further help, and several attempts to define applicable indications through prognostic stratification in this study have failed. On the other hand pediatricians and psychiatrists using pyritinol- $\mathrm{HCl}$ in everyday practice for years are as a rule convinced of their competence to select the "true pyritinol patients." This discrepancy could probably be clarified by performing a further study with basically the same design but relying on the ratings of practitioners with clinical experience with the drug in question for the selection of the test population. The disadvantage of such a design is that clinical practice does not always rely on objective criteria and, therefore, a rather complicated second step would probably be necessary to get a well defined indication list.

\section{SUMMARY}

Pyritinol- $\mathrm{HCl}$ was tested for its impact on the cognitive functions of children with learning disabilities. The test population (35 subjects) showed no significant difference of average performance in 22 cognitive parameters in comparison with the placebo group (32 subjects) after treatment. With respect to variability of

Table 3. Pyritinol and placebo group compared with respect to variances of gainscores

Variances of gainscores

Variable

1. Critical flicker frequency

2. Tachistoscope syllables

3. Tachistoscope figures

4. Tachistoscope words

5. Color blots

6. Color-word interference

7. Block design

8. Form board

9. Object assembly

10. Knox cubes

11. Paper fold

12. Benton test

13. Test $\mathrm{d} 2$

14. Repeating digits and sentences

15. Vocabulary

16. Repeating digits reversed

17. Retelling short story

18. Learning KVK structures

19. Similarities

20. Oral arithmetic

21. Dictation

22. IQ

$\begin{array}{r}\text { Pyritinol group } \\ (n=35)\end{array}$
1.114
0.300
0.139
0.567
0.593
0.784
47.538
0.056
15.852
3.207
1.152
201.138
1257.589
90.789
10.255
0.751
22.005
0.062
3.244
1.600
0.023
31.832

Placebo group

$(n=32)$

$\begin{array}{ll}F & P^{1} \\ 1.02 & \\ 1.12 & \\ 2.31 & 0.03 \\ 1.13 & \\ 2.33 & 0.02 \\ 1.04 & 0.25 \\ 1.59 & \\ 1.16 & 0.25 \\ 1.43 & \\ 1.23 & 0.10 \\ 1.79 & 0.25 \\ 1.32 & \\ 1.01 & 0.25 \\ 1.43 & \underline{0.05} \\ 1.85 & \underline{0.05} \\ 1.15 & 0.25 \\ 1.99 & \\ 1.50 & \\ 1.02 & 0.10 \\ 1.08 & \\ 1.78 & \\ 1.21 & \end{array}$

\footnotetext{
${ }^{1}$ Underlined scores indicate significance.
} 
gainscores (before or after treatment), however, there was a significantly higher variance in the pyritinol group in four parameters. The latter findings suggest medication effects for a not as yet specifiable subpopulation. The problem of how to define objective indications for a psychoactive drug was therefore considered to be the most difficult task for such a study.

\section{REFERENCES AND NOTES}

1. Arthur, G.: Point Scale of Performance Tests: Revised Form, Vol. II (The Psychological Corporation, New York, 1947)

2. Benton, A. L.: Der Benton-Test (Huber, Berne, 1968)

3. Brickenkamp, R.: Test d2. Aufmerksamkeits-Belastungs-Test (Hogrefe, Göttingen, 1968)

4. Chistoni, G. C., de Perrot, E., and Niederberger, W.: A la recherche de nouvelles méthodes d'expérimentation des médicaments psychotropes. Int. Pharmacopsychiat. Top. Prdd. 5: 54 (1970).

5. Darge, W., Liss, E., and Oeff, K.: Untersuchungen zur Pharmakokinetik und zum Metabolismus von ${ }^{35}$ S-Pyrithioxin beim Menschen. Drug Res., 9 (1969)

6. Fish, B.: Methodology in child psychopharmacology. Psychopharmacology, p. 989 (National Institute of Mental Health, Washington, D. C., 1968).

7. Fisher, S.: Child Research in Psychopharmacology. Charles C Thomas, Springfield, Ill. (1959).

8. Hardesty, F. P., and Priester, H. J.: Hamburg-Wechsier Intelligenztest für Kinder (Huber, Bern, 1966).

9. Hiskey, M. S.: Hiskey-Nebraska Test of Learning Aptitude. (Union College Press, Lincoln, Neb., 1966).

10. Hoffecker, E.: Erfahrungen mit Encephabol in der kinderärztlichen Praxis. Ther. Gegenw., 7: 913 (1964)

11. Hofovy, R., Enenkel, H. J., Gillissen, J., et al.: Zur Pharmakologie des Vitamins $B_{6}$ und seiner Derivate. Drug Res., 14: 26 (1964).

12. Jacobs, R.: Zur Psychopharmakotherapie bei sogenannten geistig behinderten Kindern unter besonderer Berücksichtigung der Encephabol-Medikation. Kinderärztl. Prax., 37: 111 (1969).

13. Kleinpeter, U., and Rösler, H. D.: Encephabol bei hirnorganisch leistungsgeminderten Normalschulkindern. Pädiatr. Grenzgeb., 7: 1 (1968).

14. Kohlmann, T., and Rett, A.: Klinische und psychologische Untersuchungen über die Wirkung von Pyrithioxin bei gehirngeschädigten Kindern und Jugendlichen. Med. We., 43: 2180 (1963).

15. Körner, $F_{\text {, }}$ and Nowak, $\mathrm{H}_{.}$: Zur Vitamin $\mathrm{B}_{6}$-und Antivitamin $\mathrm{B}_{6}$-Wirksamkeit von Pyridoxol-Derivaten unter besonderer Berücksichtigung des Pyrithioxins. Drug Res., 17: 572 (1967).

16. Latz, A.: Cognitive test performance of normal human adults under the influence of psychopharmacological agents: A brief review. Psychopharmacology, p. 83 (National Institute of Mental Health, Washington, D. C., 1968).
17. Lobrot, M.: Forschungen zur Legasthenie in Frankreich. Leseund Rechtschreibschwäche von Schulkindern. Hrsg. Ingelkamp K., Berlin, 1966).

18. Mark, H. J.: Psychodiagnostics in patients with suspected minimal cerebral dysfunction(s) (MBD). Minimal brain dysfunction in children. ( $N+S D C P$, United States Department of Health, Education and Welfare, Public Health Service Publication No. 2015, 1969).

19. Moulding, T., Onstad, G. D., and Sbarbaro, J. A.: Supervision of outpatient drug therapy with the medication monitor. Ann. Intern. Med., 73: 559 (1970).

20. Nievoll, A.: Behandlung von gehirngeschädigten Kindern. Aerztl. Prax., 40: 1664 (1964)

21. Nowak, H., and Schorre, G.: Untersuchungen zum Metabolismus von Pyrithioxin. Drug Res., 19: 11 (1969).

22. Oeff, K., Darge, W., and Liss, E.: Zum pharmakokinetischen Verhalten von ${ }^{35}$ S-Encephabol. Radioisotope in Pharmakokinetik und klinischer Biochemie, p.65 (Schattauer, Stuttgart, 1968).

23. Quadbeck, G., Landmann, H. R., Sachsse, W., and Schmidt, I.: Der Einfluss von Pyrithioxin auf die Blut-Hirnschranke. Med. Exp., 7: 144 (1962).

24. Radmayr, E.: Zur Therapie der Entwicklungsretardierung mit Encephabol. Landarzt, 43: 883 (1967).

25. Rickels, K., Cattell, R. B., Weise, C., et al.: Controlled psychopharmacological research in private psychiatric practice. Psychopharmacologia, 9: 288 (1966)

26. Sartory, G., and Rust, J.: The effects of a single administration of elitoxine on several psychological tests. Psychopharmacologia, 29/4: 365 (1973).

27. Stoll, E., Stoll, K.-D., and Gierhake, R.: Einfluss des Pyritinol-hydrochlorid auf das Leistungsverhalten konzentrations-schwacher Kinder. (Vortrag Jahrestagung Oesterreichische Gesampte für Kinderheilkunde, Salzburg, 1973).

28. Stoll, K.-D.: Personal communication.

29. Stroop, J. R.: Studies of interference in serial verbal reactions. J. Exp. Psychol., 18: 643 (1935).

30. Taber, B.: Proving New Drugs (Geron-X, Los Altos, Calif., 1969)

31. Terman, L. M., and Merrill, M. A.: Revised Stanford-Binet Intelligence Scale. (Houghton Mifflin, Boston, 1960).

32. Turner, P.: Critical flicker frequency and centrally-acting drugs. Brit. J. Ophthalmol., 52: 245 (1968).

33. Wälti, U., Salvisberg, H., and Auf der Maur, P.: Das kognitive Funktionsmuster bei Kindern Mit Trisomie 21. Schweiz. Z. Psychol., 32: 122 (1973).

34. Encephabol, E. Merck, Darmstadt.

35. The authors wish to thank especially to Drs. Y. Neumann and K. D. Stoll for their substantial help with the technical organization of the study and the evaluation of data.

36. This research was supported by E. Merck, Darmstadt and the "Schweizerischer Nationalfonds zur Förderung der wissenschaftlichen Forschung," Project No. 4.62.72.

37. Requests for reprints should be addressed to: U. Wälti, Ph.D., Abteilung für Entwicklungsstörungen, Medizinische Kinderklinik der Universitat Bern, Inselspital, 3000 Berne (Switzerland).

38. Accepted for publication May 7, 1975.
Cystic fibrosis duodenal fluids exocrine glands polyamines saliva spermidine spermine sweat

\title{
Polyamines in Cystic Fibrosis
}

\author{
F. A. MCEVOY(25) AND C. B. HARTLEY \\ University of Birmingham, Institute of Child Health, Birmingham, United Kingdom
}

\section{Extract}

Polyamine concentrations have been measured in blood samples from a series of cystic fibrosis (CF) patients and control subjects. Analyses were made by a fluorometric method, in which the amines were reacted with dansyl chloride and separated by thin layer chromatography on Kieselguhr. There was no significant difference between the polyamine concentrations of blood samples from CF patients and control subjects. Also, the spermidine-spermine ratio was similar in both groups. Polyamines were also analyzed in exocrine fluids, and although none could be detected in either CF or control sweat or saliva, significant amounts of spermine and spermidine were present in all samples of bile and duodenal fluids. It thus seems likely that the biliary route is a significant pathway in the human for excretion of polyamines.

\section{Speculation}

The observation that polyamines are excreted in considerable concentrations via the bile in children may be of interest in view of the reports of elevated urinary polyamine concentrations in neoplastic states. Since measurable amounts of spermine and spermidine 